\title{
ANÁLISIS DE UN COLECTIVO SOCIO-PROFESIONAL MINUSVALORADO: LOS OFICIALES DE PLUMA EN LA ESPAÑA MERIDIONAL SEGÚN EL CATASTRO DE ENSENADA
}

\author{
ANALYSIS OF A SOCIO-PROFESSIONAL GROUP \\ UNDERESTIMATED: OFFICIALS OF NOTARIES IN SOUTHERN \\ SPAIN ACCORDING TO THE CADASTRE OF ENSENADA
}

\author{
Lorena C. BARCO CEBRIÁN \\ Universidad de Málaga
}

Resumen: El presente trabajo trata de mostrar la realidad de uno de los oficios quizás más importantes para los historiadores, pero que sin embargo no se ha tratado como debiera por la historiografía, eclipsado por el análisis y estudio de los fedatarios públicos. El de oficial de pluma ha sido uno de los oficios que nos ha permitido disponer de grandes fuentes historiográficas, nos referimos a la documentación notarial y concejil, ya que pese a que eran los escribanos los que ostentaban tal quehacer, en la práctica, en la mayoría de las ocasiones delegaban el proceso de escrituración en sus diferentes oficiales de pluma, personas que se estaban formando en las oficinas de aquellos fedatarios. No obstante, la aproximación a esta figura se antoja difícil, ya que no son pródigas las alusiones que nos encontramos de ellos y de sus obligaciones en la documentación conservada. Sin embargo, para mediados del siglo de la Ilustración contamos con una de las fuentes históricas más importantes del momento, se trata del conocido como Catastro de Ensenada. Precisamente a través del análisis y estudio de sus Respuestas Generales hemos podido acercarnos a este tipo de oficio, conocer quiénes eran aquellos hombres que realizaban tamaña labor y cuál era su salario por la realización de sus quehaceres. Asimismo, se ha procedido a la consulta de documentación custodiada en archivos locales malacitanos para tener un conocimiento más certero sobre la situación real de aquellos oficiales. Para ello nos situamos por tanto en un período concreto, los años centrales de la centuria dieciochesca; y, del mismo modo, analizamos este oficio en un espacio geográfico específico, dentro del sur peninsular tomamos como epicentro la provincia malagueña. 


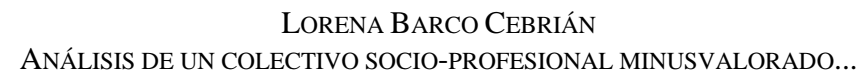

Palabras clave: Institución notarial, oficiales de pluma, siglo XVIII, Catastro de Ensenada.

Abstract: This paper tries to show the reality of one of the trades
more important for historians, the officials of the notaries. The
work of these officials has allowed us to have great historical
sources; we refer to the notarial documentation and documenta-
tion of the City Council. They were the executive arm of the pub-
lic notaries. Nevertheless, the approach to this figure seems diffi-
cult, since we do not find lavish allusions of them or any of their
obligations in the documentation preserved. However, we have
one of the most important historical sources by middle of Eight-
eenth century; this is known as the Cadastre of Ensenada. We
have been able to approach this type of job through analysis and
study of the Cadastre, so we know who were those men who did
this huge undertaking and what was his salary for performing
their tasks. In addition, we proceeded to the consultation of doc-
umentation kept in local files to have a more accurate understand-
ing of the real situation of those officials.

Keywords: Notarial institution, officials of pen, $18^{\text {th }}$ century, Catastro of Ensenada.

\section{A MODO DE INTRODUCCIÓN}

La institución notarial ha sido objeto de numerosos análisis y estudios por parte de la historiografía española desde el siglo pasado. Así han sido estudiadas todas las épocas desde que apareciera la institución notarial en Italia allá por el siglo XII ${ }^{1}$. Pero lo cierto es que no todos los períodos y no todas las áreas geográficas han sido estudiados equitativamente. Así tenemos que la época medieval ha sido analizada en numerosas ocasiones ${ }^{2}$, al igual que el tránsito a la Modernidad ${ }^{3}$.

${ }^{1}$ A. RIESCO TERRERO, "Notariado y documentación notarial castellano-leonesa de los siglos X-XIII”, en RIESCO TERRERO, A. (coord.), I Jornadas sobre Documentación jurídicoadministrativa, económica-financiera y judicial del reino castellano-leonés (siglos X-XIII), Madrid, 2012, pp. 130-164.

${ }^{2}$ F. ARRIBAS ARRANZ, "Los escribanos públicos en Castilla durante el siglo XV", en Centenario de la Ley del Notariado, vol. I., Madrid, 1964, pp. 165-260. A. RIESCO TERRERO, "El notariado castellano bajomedieval (siglos XIV-XV): Historia de esta institución y de la producción documental de los notarios hasta el reinado de Isabel I de Castilla”, en J.C. GALENDE DÍAZ (coord.), II Jornadas Científicas sobre Documentación de la Corona de Castilla (siglos XIII-XV), 2003 pp. 175-225. J. BONO HUERTA, Historia del derecho notarial español, Madrid, 1979, 2 vols. A. LÓPEZ GUTIÉRREZ, “Oficio y funciones de los escribanos de la cancillería de Alfonso X”, Historia, Instituciones, Documentos, 31 (2004), pp. 353-367. P. OSTOS SALCEDO, 


\author{
LORENA BARCO CEBRIÁN \\ ANÁLISIS DE UN COLECTIVO SOCIO-PROFESIONAL MINUSVALORADO...
}

Sin embargo, dentro de las centurias que integran la conocida como Edad Moderna, no todos los períodos han sido tratados por igual, así el Siglo de Oro español ${ }^{4}$ ha sido objeto de multitud de trabajos, mientras que el siglo XVIII, al que nosotros nos referimos, no ha sido tan estudiado, y ha empezado a ser objeto de análisis hace relativamente poco tiempo ${ }^{5}$.

“Los escribanos públicos de Palma del Río (Córdoba) 1345-1400”, Historia, Instituciones, Documentos, 17 (1990), pp. 143-162. P. OSTOS SALCEDO, “Aranceles notariales de Córdoba (14821495), Historia, Instituciones, Documentos, 25 (1992), pp. 503-535. E. PONDÉ, “La organización notarial en la Edad Media”, Revista del Notariado. Órgano del Colegio de Escribanos de la Capital Federal, LXX/960 (noviembre-diciembre 1966), pp. 1375-1386. D. REINALDOS MIÑARRO, "Los escribano de cámara y del número de Lorca (Murcia) a finales de la Edad Media a través de los protocolos notariales (1466-1521)”, Miscelánea Medieval Murciana, XXXIV (2010), pp. 103108.

${ }^{3}$ P. J. ARROYAL ESPIGARES, Las escribanías públicas de Málaga (1487-1516), Málaga, 1991. Ma. L. PARDO RODRÍGUEZ, P. OSTOS SALCEDO (coords.), El notariado andaluz en el tránsito de la Edad Media a la Edad Moderna: I Jornadas Sobre el Notariado en Andalucía, del 23 al 25 de febrero de 1994, 1995. B. CASADO QUINTANILLA, "Nombramientos de escribanos públicos en Ávila, y sus circunstancias, en tiempos de los Reyes Católicos”, Espacio, Tiempo y Forma. Serie III. $H^{a}$ Medieval, 17 (2004), pp. 115-129. P. OSTOS SALCEDO, M ${ }^{\mathrm{a}}$. L. PARDO RODRÍGUEZ (edits.), Estudios sobre el Notariado Europeo (Siglos XIV-XV), Sevilla, 1997. Ma . L. PARDO RODRÍGUEZ, "Notariado y Monarquía: los escribanos públicos de la ciudad de Sevilla en el reinado de los Reyes Católicos", Historia, Instituciones, Documentos, 19 (1992), pp. 317326. Ma. L. PARDO RODRÍGUEZ, Señores y escribanos. El notariado andaluz entre los siglos XIV y XVI, Sevilla, 2002.

${ }^{4}$ M. A. MORENO TRUJILlO, J. M. de la OBRA SIERRA, M. J. OSORIO PÉREZ, El Notariado Andaluz: Institución, práctica notarial y archivos. Siglo XVI, II Jornadas sobre el Notariado en Andalucía, Granada, 22 a 24 de abril de 2011, Granada, 2011. A. CASTILLO GÓMEZ, "Cultura escrita y actividad escribanil en el Siglo de Oro", en E. VILLALBA PÉREZ, D. TORNÉ (eds. lits.), El nervio de la república: el oficio de escribano en el Siglo de Oro, Barcelona, 2010, pp. 351-370. A. CASTILLO GÓMEZ, Entre la pluma y la pared: una historia social de la escritura de los Siglos de Oro, Madrid, 2006. E. VILLALBA PÉREZ, D. TORNÉ (eds. lits.), El nervio de la república: el oficio de escribano en el Siglo de Oro, Barcelona, 2010. D. GARCÍA HERNÁN, "Señorío y escribanos señoriales en Castilla en el Siglo de Oro", en J. J. BRAVO CARO, L. SANZ SAMPELAYO (coords.), Población y grupos sociales en el Antiguo Régimen, vol. 1, Málaga, 2009, pp. 661-676. E. MENDOZA GARCÍA, Los escribanos de Málaga en el Siglo de Oro (1598-1700), tesis doctoral, Universidad de Málaga, Málaga, 2005. E. VILLALBA, "Sospechosos en la verdad de lo que pasa ante ellos. Los escribanos de la corte en el Siglo de Oro: sus impericias, errores y vicios”, Litterae. Cuadernos sobre Cultura Escrita, 2 (2002), pp. 121-149.

${ }^{5}$ P. J. ARROYAL ESPIGARES, "Nómina de notarios, escribanos y oficiales de pluma en Andalucía a mediados del siglo XVIII, según el Catastro de Ensenada", en http://riuma.uma.es/ xmlui/handle/10630/4860?show=full. L. ESCUDERO ESCUDERO, "Los escribanos manchegos a mediados del siglo XVIII. Una aproximación a su patrimonio agrario”, en Mª J. PÉREZ ÁLVAREZ, A. MARTÍN GARCÍA (coords.), Campo y campesinos en la España Moderna; culturas políticas en el mundo hispano, vol. 2, 2012, pp. 1337-1347. M. A. EXTREMERA EXTREMERA, "Escribanos, cultura escrita y sociedad en la España Moderna (siglos XVI-XVIII)", Litterae: cuadernos sobre cultura escrita, 3-4 (2003-2004), pp. 187-206. G. F. FERNÁNDEZ SUÁREZ, "Una primera aproximación a los escribanos del concejo de Lugo entre los siglos XVI y XVIII”, en C. BALIÑAS PÉREZ, G. F. FERNÁNDEZ SUÁREZ (coords.), Sub Urbem: Historia, sociedade e cultura da cidade: Actas do VII Curso de Primavera, Facultade de Humanidades de Lugo, 3-6 de 
Concretamente, en nuestro ámbito geográfico más cercano, el siglo XVIII apenas había sido analizado en cuanto a la institución notarial se refiere ${ }^{6}$. Pero si nos centramos en nuestro objeto de análisis en el presente trabajo, los oficiales de pluma, estos han sido minusvalorados por la historiografía, quizás haya sido por la falta de documentación y fuentes para su estudio, pero tampoco cabe duda que también ha sido porque ha quedado eclipsado por la figura del fedatario ${ }^{7}$. Sin embargo, no hay que olvidar que en la práctica el gran peso de la labor escrituraria que se producía en un escritorio público era realizada por los diferentes oficiales de pluma que estaban al servicio y aprendiendo para y con el escribano público en cuestión. Por ello, creemos de suma importancia acercarnos a este oficio, bastante desconocido para la historiografía, pero de una gran importancia para la historia, al ser uno de los ejecutores de una gran parte de nuestras fuentes historiográficas para el estudio de la Modernidad.

\section{CONTEXTUALIZACIÓN HISTÓRICA}

El siglo XVIII es un período atrayente para cualquier historiador, ya que en él se produce la denominada como Ilustración, epíteto con el que es conocida dicha centuria. Por lo tanto se trata de un período histórico donde se produce la ascensión al trono de la dinastía de los Borbones, salpicada de guerras y conflictos, pero que curiosamente con Fernando VI se producirá un cambio, no solo en cuanto a la paz se refiere, sino que también se produce una reforma a todos los nive-

maio de 2011, 2012, pp. 143-159. Mª LÓPEZ DÍAZ, “Una aproximación a la institución notarial en Santiago: escribanos y notarios a mediados del siglo XVIII”, Estudios mindonienses: Anuario de estudios histórico-teológicos de la diócesis de Modoñedo-Ferrol, 8 (1992), pp. 421-456. A. MARCHANT RIVERA, "Los escribanos españoles del siglo XVIII a la luz de la literatura de viajes: viaje por España de Joseph Townsend”, Baética. Estudios de Arte, Geografía e Historia, 28 (2006), pp. 325-335.

${ }^{6}$ M. REDER GADOW, "Breve estudio sobre los escribanos públicos malagueños a comienzos del siglo XVIII”, Baética: Estudios de arte, geografía e historia, 5 (1982), pp. 195-205. A. SÁNCHEZ MAIRENA, "Escribanías públicas y del concejo de Marbella (Málaga) y su jurisdicción entre los siglos XV y XVIII”, en E. VILLALBA PÉREZ, E. TORNÉ (eds. lits.), El nervio de la república: el oficio de escribano en el Siglo de Oro, Barcelona, 2010, pp. 119-143.

7 V. GAYOL, Laberintos de justicia. Procuradores, escribanos y oficiales de la Real Audiencia de México (1750-1812), México, 2007, 2 vols. S. PÉREZ HERNÁNDEZ, "Dos movimientos contestatarios en el tránsito del siglo XVI al XVII: los escribanos del número y los oficiales agavillados de Bilbao", en M. R. PORRES MARIJUÁN (ed. lit.), Poder, resistencia y conflicto en las provincias vascas (siglos XV-XVIII), Bilbao, 2001, pp. 185-218. 
les ${ }^{8}$. A ello se acompaña un crecimiento demográfico en prácticamente todo el territorio nacional, y precisamente para tener conocimiento de los recursos de los que disponía la Corona surge una figura importante, nos referimos a Zenón de Somodevilla y Bengoechea, más conocido como Marqués de la Ensenada. Dicho personaje se encumbró en lo más alto de las esferas políticas del país, pero también sufrió un descenso acelerado por dos veces, que lo llevó finalmente a ser desterrado ${ }^{9}$. Pero antes de llegar a ese fin, Ensenada realizó numerosos cambios y reformas en España, una de ellas y quizás por la que ha pasado a ser conocido a lo largo de la historia sea su plan de Única Contribución, que aunque finalmente fue fallida, lo cierto es que nos ha dejado una de las fuentes históricas más importantes para conocer la sociedad de mediados del XVIII, el conocido como Catastro de Ensenada $^{10}$. Se trata este de una radiografía de la sociedad española del momento, donde se catastraron 22 provincias $^{11}$ dando lugar a más de 80.000 manuscritos $^{12}$ que son una joya para cualquier historiador. A través de sus páginas podemos estudiar y acercarnos a numerosos rincones de la sociedad española del momento. Nosotros, en esta ocasión, lo hemos utilizado para profundizar en el conocimiento de un estrato de la sociedad minoritario, aquellos que trabajaban para los escribanos, los denominados como oficiales de pluma.

\footnotetext{
${ }^{8}$ C. GÓMEZ-CENTURIÓN JIMÉNEZ, “La reforma de las Casas Reales del marqués de la Ensenada”, Cuadernos de Historia Moderna, 20 (1998), pp. 59-83. J. L. GÓMEZ URDÁNEZ, El Proyecto Reformista de Ensenada, Lérida, 1996.

${ }^{9}$ Para ampliar sobre la figura de Zenón de Somodevilla y Bengoechea ver: F. ABAD LEÓN, El Marqués de la Ensenada, Su Vida y Su Obra, I y II, Madrid, 1985. J. L. GÓMEZ URDÁÑEZ, “Ensenada, hacendista ilustrado”, en I. DURÁN BOO, C. CAMARERO BULLÓN (coords.), El Catastro de Ensenada: magna averiguación fiscal para alivio de los vasallos y mejor conocimiento de los reinos: 1749-1756, Madrid, 2002, pp. 83-100. C. GONZÁLEZ CAIZÁ, La red política de Zenón de Somodevilla y Bengoechea, Marqués de la Ensenada, tesis doctoral, Universidad de La Rioja, Logroño, 2003. D. OCHAGAVÍA FERNÁNDEZ, “Don Cenón de Somodevilla, I Marqués de la Ensenada”, Berceo, 13 (1949), pp. 511-524.

${ }^{10}$ Ver C. CALVO ALONSO, "El catastro de Ensenada proyecto de única contribución en la Corona de Castilla”, en A. SEGURA I MAS, I. CANET RIVES, (coords.), El Catastro en España, vol. 1, 1988, pp. 89-112. C. CAMARERO BULLÓN, "El Catastro del Marqués de la Ensenada como fuente demográfica: La documentación a nivel local”, Estudios Geográficos, XLVI, 178-179 (1985 febrero-mayo), pp. 137-157. J. M. DONÉZAR DÍEZ DE ULZURRUN, "El catastro de Ensenada y su proceso de formación (1750-1760), Revista de la Facultad de Geografía e Historia, 4 (1989), pp. 207-224. El Catastro de Ensenada. Magna averiguación fiscal para alivio de vasallos y mejor conocimiento de los Reinos. 1749-1756, Madrid-Alcalá de Henares, 2002. D. MATEOS DORODO, "La Única Contribución y el Catastro de Ensenada (1749-1759)”, La época de Fernando VI. Textos y estudios del siglo XVIII, 9 (1981), pp. 227-240. A. MATILLA TASCÓN, La Única Contribución y El Catastro de Ensenada, Madrid, 1947, pp. 18-28.

${ }^{11}$ Quedando fuera de las pesquisas catastrales Cataluña, Aragón, las Vascongadas, las islas Canarias y Mallorca.

12 C. CAMARERO BULLÓN, “Averiguarlo todo de todos: El Catastro de Ensenada”, Estudios Geográficos, LXIII, 248/249 (2002), pp. 493-531.
} 


\section{OFICIOS ANEJOS AL DE FEDATARIO}

Dentro de los oficios anejos o vinculados al de escribano público, hallamos aquellos que de una forma más o menos indirecta tienen relación con este grupo socio-profesional, pero sobre todo, que tienen una relación más estrecha con el mundo escriturario que el resto de la sociedad. Es decir, quedan incluidos en este grupo aquellos oficios que de un modo u otro tienen relación con la escritura, ya sea porque la enseñan o bien porque sea un instrumento principal para acometer sus quehaceres laborales. Ellos conforman las capas alfabetizadas de la sociedad malagueña a mediados del siglo XVIII. Incluimos aquí a los oficiales de pluma, brazo ejecutor de la labor escrituraria de los fedatarios; los maestros de primeras letras, de quienes dependían buena parte de la formación de aquellos pocos privilegiados que podían acceder a un mínimo de educación; los preceptores de gramática, menor en número que sus colegas los maestros de primeras letras, y por lo tanto, con un público también menor, por lo que la formación en este escalón superior dentro de la educación estaba reservada todavía a un número menor de personas; y, por último, los abogados, profesionales que vehiculizaban sus quehaceres profesionales a través de la escritura, y que también mantenían una relación más o menos estrecha con los miembros que componían la institución notarial, sobre todo, aquellos abogados que trabajaban para el cabildo municipal y que mantenían una estrecha relación profesional con los escribanos de cabildo. Ya que el abogado necesitaba de la labor del fedatario de ayuntamiento para poder defender a la ciudad ante la justicia, solicitando su ayuda en la expedición de copias de las escrituras pertinentes para poder defender con garantías los intereses de la ciudad.

Todos los oficios mencionados anteriormente tienen como característica principal el utilizar la escritura como su medio principal de realizar sus labores, sin embargo, tal vez el que más está vinculado al de fedatario sea el de oficial de pluma, ya que gran parte del grueso del trabajo que tenían que realizar los escribanos en la praxis lo realizaban los diferentes oficiales que trabajaban con él. De ahí que en realidad un gran volumen de las escrituras protocolizadas por los escribanos, sobre todo, los denominados como públicos o numerarios, fueran ejecutadas por estos oficiales que estaban formándose en el mencionado escritorio. Según las características del escritorio público que analicemos nos encontramos con uno o con varios oficiales, generalmente más de uno, aunque uno de ellos era el denominado como oficial mayor, que se encontraría a cargo del escritorio público en ausencia del fedatario principal. 


\section{LOS OFICIALES DE PLUMA MALAGUEÑOS EN EL SIGLO XVIII: FORMACIÓN, CURSUS HONORUM, INTEGRANTES Y POSI- CIÓN SOCIAL}

Oficiales, mozos y escribientes podían llegar a alcanzar con los conocimientos logrados por el ejercicio diario en una escribanía el grado de fedatario. El oficial era un personaje con cierta categoría profesional y la persona que certificaba los asuntos, y quizá por ello, quien tramitara los diferentes casos de la escribanía antes de llegar a la escrituración o preparación de esta. Los escribientes eran amanuenses que debían preparar el documento, ya en limpio ${ }^{13}$. Por lo tanto, eran el brazo ejecutor de la actuación escrituraria de una escribanía, ya fuera pública o de cabildo, además de aquellas notarías apostólicas o escribanías especiales, las cuales también contaban con la ayuda de uno o varios oficiales de pluma.

No nos consta el nombre de ninguno de los oficiales de pluma si utilizamos como única fuente el Catastro de Ensenada, además es poca la constancia que hay de ellos en el referido Catastro, apenas son nombrados en unos pocos pueblos, destacando la presencia de ellos en Antequera, donde el Catastro contabiliza 16 de estos escribientes. Por lo que es de suponer que en el resto de las ciudades de un peso más específico dentro de la provincia malagueña, también debieron contar con un número elevado de estos oficiales. De hecho se constata su presencia en todas las escribanías numerarias para la capital malagueña, contando cada una de ellas con uno o dos, e incluso en algunos casos tres de estos profesionales, siendo además los testigos de muchas de las escrituras protocolizadas en las escribanías donde trabajaban. Tenemos constancia de ellos en siete pueblos o lugares de la provincia malagueña. De entre ellos destacan esos 16 mencionados para Anteque$\mathrm{ra}^{14}$, siendo el resto de villas donde se mencionan Campillos ${ }^{15}$, donde solo hay uno; Cañete ${ }^{16}$, también con uno; Churriana ${ }^{17}$, con dos escribientes; Estepona ${ }^{18}$, donde no consta el número de ellos pero se evidencia que tendría que haber al

${ }^{13}$ P. J. ARROYAL ESPIGARES, E. CRUCES BLANCHO, Mª. T. MARTÍN PALMA, Las escribanías públicas de Málaga (1487-1516), Málaga, 2007, p. 76.

14 (A)rchivo (G)eneral de (S)imancas, Dirección General de Rentas, Catastro de Ensenada, Respuestas Generales, libro 560, f. 247r.

${ }^{15}$ Ibídem, libro, 561, f. 416r.

${ }^{16}$ Ibídem, f. 462r.

${ }^{17}$ Ibídem, libro 284, ff. 267r-v.

${ }^{18}$ Ibídem, libro 287, f. 118r. 
exponernos que se les consideraba de salario dos reales diarios a cada uno de estos oficiales; y, por último, otro más en Teba ${ }^{19}$.

Por lo tanto, estamos ante un desconocimiento prácticamente total sobre este grupo para la provincia malagueña del Setecientos, ya que tenemos que suponer que la mayoría de escribanos contarían al menos con algún ayudante, sobre todo en los grandes núcleos de población como podrían ser Ronda, Vélez-Málaga e incluso la capital malagueña, pero sin embargo no han quedado reflejados en la documentación catastral. Esta hipótesis se apoyaría con los 16 oficiales mencionados para Antequera, por lo que esto nos hace suponer que si había esta cantidad para este municipio, alrededor de una cifra semejante debería de aparecernos para otros núcleos de población similares a aquella, pero que sin embargo han sido obviados en la documentación. Por ejemplo, Francisco González Nieto era escribano numerario de la capital malagueña en el año 1753, y tenía más de dos oficiales de pluma a su servicio como se desprende del siguiente fragmento:

En este cavildo se uio el informe del presente escribano puesto en el memorial de Antonio Joseph de Espejo, Don Julian de Fragua, y demás oficiales de pluma de la escribanía de Don Francisco Nieto ${ }^{20}$.

Como venimos apuntando, en el Catastro es poca la constancia que hay de estos amanuenses, ya que apenas son nombrados en algunos de los pueblos estudiados, destacando la presencia de estos en Antequera. Por lo tanto, cabe preguntarse ¿por qué el silencio casi absoluto en el resto de villas y ciudades?; por ejemplo, en Málaga no hemos constatado su presencia en las Respuestas Generales, sin embargo, si tenemos en cuenta que en Antequera había dieciséis de estos escribientes, suponemos que en Málaga como mínimo debería de haber un número parecido, si no mayor, y que sin embargo no han quedado reflejados. No obstante, si buscamos a estos oficiales en otras fuentes como pueden ser las Actas Capitulares del concejo malacitano, la situación es diferente. Se nos constata la presencia de los ayudantes de los fedatarios principales del cabildo malagueño. Además, su presencia en la documentación es bastante asidua, hallando importante información sobre estos profesionales de la pluma malagueños.

Conocemos la existencia de dos oficiales de pluma de los dos escribanos mayores del cabildo malagueño. La situación económica de estos amanuenses era muy precaria en aquellos momentos, quejándose constantemente al cabildo por el

${ }^{19}$ A. G. S., Dirección General de Rentas, Catastro de Ensenada, Respuestas Generales, libro 563, f. 544v.

${ }^{20}$ (A)rchivo (M)unicipal de (M)álaga, AA. CC., vol. 144, ff. 177r-v. 
impago de su salario e incluso de los trabajos extras que realizaban para el concejo malagueño. El salario les era abonado en dos pagos anuales, uno a principios de año y otro en julio. Por lo que el pago era semestral, siendo de doscientos reales cada uno de ellos, por lo que el montante total que percibía cada oficial al año era de tan solo cuatrocientos reales de vellón.

La ziudad libro sus rentas de propios a don Gerardo Luis Marmolejo y don Antonio Paredes y Aguilar, oficiales mayores de las dos escriuanias de cavildo, quatrocientos reales de vellón, doscientos reales a cada uno, por el trauajo que han tenido en los seis meses desde primero de julio de setecientos y zinquenta hasta fin de diciembre de el en escriuir el libro capitular, testimonios, consultas ${ }^{21}$.

Dicho salario, comparado con el que percibía cada escribano de cabildo o público $^{22}$, era una cantidad prácticamente irrisoria, máxime cuando en realidad sabemos que el grueso del trabajo de la escribanía, en cuanto a su vertiente escrituraria se refiere, recaía precisamente en estos amanuenses. Por lo tanto era común que este oficio se compaginara con otros que cumplimentaran el salario del oficial; así sabemos que Antonio Paredes fue nombrado también como síndico personero $^{23}$. Si la muerte no le hubiera sobrevenido tan temprano al mencionado Antonio Paredes, como mostraremos a continuación, quizás hubiera llegado a ser escribano de cabildo de la capital, ya que parece ser que el cursus honorum de estos era precisamente el que estaba encaminando el oficial.

Este cursus honorum, que también se puede apreciar en la carrera de los escribanos numerarios, para los escribanos de cabildo era ser oficial de una de las escribanías mayores de cabildo, luego síndico personero, y de ahí pasar a servir la escribanía de cabildo. Dicha trayectoria laboral la vemos en la persona de Francisco Joseph González Nieto, y era la misma que estaba intentando transitar Antonio Paredes, ya que cuando Francisco Joseph González Nieto es nombrado como escribano de cabildo, deja vacante un puesto de síndico personero al que concurren Antonio Paredes y Bernardino Valenzuela. El procedimiento era votarlo en la sesión capitular, al igual que ocurría con el resto de los cargos capitulares. Una vez votado, Antonio Paredes consiguió once votos y su oponente uno más, doce, por lo que se nombró como tal síndico personero a Bernardino Valenzuela ${ }^{24}$. Pero todo ello nos hace suponer que en un futuro Antonio Paredes seguiría intentado ir

\footnotetext{
${ }^{21}$ A. M. M., AA. CC., vol. 142, f. 10v.

22 De media los escribanos públicos de la capital malagueña recibían una cantidad de 2.750 reales de vellón al año. A. G. S., Dirección General de Rentas, Catastro de Ensenada, Respuestas Generales, libro 595, ff. 451r-453v.

${ }^{23}$ A. M. M., AA. CC., vol. 142, f. 71 v.

${ }^{24}$ Ibídem.
} 
subiendo escalafones en la jerarquía concejil, tal y como lo hacían sus compañeros del cabildo malacitano. Su empeño en este ascenso, buscando una remuneración económica mayor para poder mantener a su familia, fue el hecho de presentarse para servir la escribanía de cabildo malagueña, que quedó vacante a la muerte del escribano Juan de Rute y Torre, algo que tampoco consiguió ${ }^{25}$. Pero su fallecimiento fue temprano, truncando así toda posibilidad de ascenso social, que por otro lado, tenía todas las posibilidades de que se produjera. Aun así, la precariedad económica era patente en estos oficiales, ello se constata por el hecho de que la situación familiar de estos oficiales también era inestable. Ejemplo de ello lo encontramos en un escrito hallado en una de las actas capitulares del cabildo malacitano. En un papel de pequeño tamaño, inserto en uno de los legajos que componen la colección de actas capitulares de los cabildos que tuvieron lugar en Málaga, se puede leer lo siguiente:

\begin{abstract}
Yllustrisima Ciudad:
Maria Paredes de edad de cinco a seis años, hija de Don Antonio Paredes y de Doña Theresa Garabeytia, huérfana de padre y madre, a los pies de vuestra illustrisima. Dise se halla perdida pidiendo limosna por la falta de dichos sus padres, sin mas recurso que el de la Dibina providencia, y siendo como fue el padre de la suplicante criado de vuestra señoria a quien sirvió con el mayor esmero.

Suplica rendidamente se sirva conceder su licencia para que la resiban en el colejio de Niñas Huerfanas mediante a concurrir en la suplicante las qualidades que apetece la constituzion. Favor que espera de la benignidad de vuestra señoria yllustrisima a que la Dibina guarde y prospere... su santa gracia ${ }^{26}$.
\end{abstract}

Antonio Paredes fue el oficial mayor del escribano mayor del cabildo malacitano, Antonio Calvo, y ambos fallecieron el mismo año de 1751, aunque el óbito del escribano fue anterior al de su oficial. Así, cuando fallece Antonio Calvo, Antonio Paredes y Aguilar presenta un memorial al cabildo malagueño pidiendo que se le mantenga en su puesto, donde llevaba más de diez años:

Don Antonio Paredes y Aguilar oficial mayor de la escriuania de cavildo que usaua don Antonio Calbo defunto...tendiendo se le mantenga en ella de tal oficial mayor en atención a sus buenos seruisios de mas de diez años a esta parte que lo usa, habiendo en todo desempeñado su obligación como a la ciudad le consta” ${ }^{27}$.

Era precisamente el oficial, Antonio Paredes y Aguilar, quien realizaba la mayor parte del trabajo. Donde se da a conocer la muerte de ambos y se pide un examen de los libros capitulares para verificar la letra:

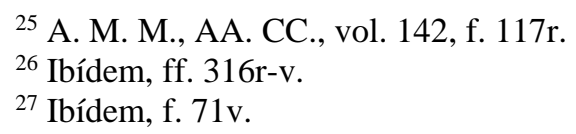


Auiendo muerto este presente año Don Antonio Caluo, escriuano que era de cauildo, y a cuyo cargo estubo la exzecucion de todos los celebrados el año próximo pasado, y autorizados por que fue el que los presensio. Se encuentran muchos de dichos acuerdos sin auerlos firmado, aunque si escrito todos a el parecer en el libro capitular. Y lo mismo los borradores de dichos acuerdos, letra y mano de Don Antonio Paredes, que tambien en este presente año ha muerto, como oficial mayor que era del dicho Don Antonio Caluo. En fuerza de lo qual y para en el modo posible verificar dicha realidad, suplico a vuestra merced se sirua mandar que personas que tenia conocimiento de la letra del dicho Don Antonio Paredes vean la letra de dichos acuerdo tanto en los borradores como en limpio. Y aclaren si toda ella según su conocimiento es sierta de mano de dicho Don Antonio Paredes y la misma que acustumbraua escriuir y asi ejecutado ${ }^{28}$.

Dejando de lado lo que el fragmento anterior relata sobre la desidia de los quehaceres de estos fedatarios, lo que nos interesa en esta ocasión es la figura de Antonio Paredes para analizar el trabajo de los oficiales mayores de cabildo. Cuando se pide el examen tanto de los borradores como de su puesta en limpio en los libros capitulares, en ningún momento se habla de la letra del escribano mayor, Antonio Calvo, sino de aquellos que entienden y saben cuál era la letra de su oficial. Lo que nos lleva a pensar que el ejecutor real tanto de los borradores como después del libro capitular era en realidad el oficial, además de atender testimonios y consultas $^{29}$. El grueso del trabajo de la escribanía de cabildo malagueña recaía así en los oficiales de pluma o amanuenses, los que por otro lado, eran los que percibían un salario más bajo.

En 1751 los dos oficiales mayores de las escribanías de cabildo eran Gerardo Luis Marmolejo y siguiendo en su cargo, Antonio Paredes y Aguilar ${ }^{30}$. Para el año siguiente de 1752, seguía en el mismo puesto el mencionado Gerardo Luis Marmolejo, pero Antonio Paredes había fallecido, por lo que el otro oficial era Pedro Cano Castillo ${ }^{31}$, ocupando ambos sendos cargos también los años siguientes de $1753^{32}$ y $1754^{33}$; pero en este último año Gerardo Luis Marmolejo promocionó en ese cursus honorum y fue nombrado escribano real por título expedido en el Buen Retiro a diez de marzo del mencionado año ${ }^{34}$. Los quehaceres de estos oficiales de pluma no se circunscribían únicamente a realizar los borradores y puesta en limpio de los diferentes libros o protocolos de la escribanía que servían, sino

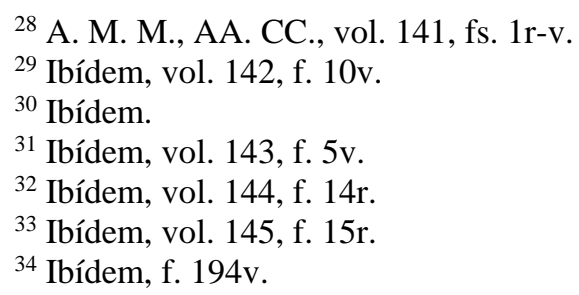


que también hacían una labor paleográfica, buscaban documentación requerida por parte de los interesados, y sacaban copias de las diferentes escrituras, bien para presentarlas ante la justicia o bien por pérdida del original por parte del interesado. Así en sesión capitular celebrada el 29 de marzo del año 1753 se hacen referencias a algunas de las labores mencionadas:

Yllustrisima ciudad, Antonio Joseph Espejo, don Julian de Fragua, y demás oficiales de pluma, que de orden de vuestra señoria están sacando las copias de los reales privilegios que obtiene vuestra señoria, puesto a sus pies con la mayor veneración. Dizen que teniendo copiados treze reales despachos muy difusos y los mas de letra antigua y mui difícil, y estando siguiendo la saca de los demás en lo que han ocupado muchos días y con un cresido trabajo, y siendo notorio no tener otra cosa con que sustentarse sino es con su trabajo personal. Se hallan con muchas estrechezes por lo que recurren a la eroica piedad de vuestra señoria, a quien suplican se dignase librarles con que puedan subbeuir a el remedio de sus atrazos con aquella cantidad que la elevada comprehencion de vuestra señoria reconosca merecer su trabajo. Para que assi puedan acavar de servir a vuestra señoria en la dicha saca de copias, fabor que esperan merecer de la equitativa clemencia de vuestra señoria, cuya grandeza prospere Dios en el mayor auge ${ }^{35}$.

Del fragmento antecedente se destilan varios de los quehaceres mencionados, sacar copias, labores paleográficas, ya que como se indica tienen que leer y sacar copias de escrituras antiguas, por lo tanto tienen que llevar a término labores paleográficas para realizar bien su trabajo. Pero también se desprende la precariedad de tal oficio. Ya que lo principal de la escritura es la queja del impago por su trabajo por parte de las autoridades municipales, trabajo que les reporta muy pocos beneficios pecuniarios, y que no les permite prácticamente subsistir dignamente. De ahí que se vean en la necesidad de pedir una remuneración excepcional al alcalde mayor de la ciudad malagueña, que además dejan a su voluntad. Otro ejemplo de la precariedad económica de este oficio lo encontramos en una escritura inserta en la sesión capitular celebrada el 23 de agosto de 1754 en el cabildo malagueño:

En este cauildo se hizo presente y leyó un memorial de don Pedro Cano Castillo, oficial mayor de la scribania de cauildo. En el que manifiesta el ynsesante desbelo y aplicación con que ha seruido y esta siruiendo en dicha scribania y los cortos o ningunos emolumentos que esta produse. Motiuo porque se halla en la mayor ynfellicidad y sin poder buscar por otro medio el presiso alimento de su familia. Por lo que manifestaua asi para que la ciudad acordase lo que fuese de su agrado ${ }^{36}$.

\footnotetext{
${ }^{35}$ A. M. M., AA. CC., vol. 144, fs. 178r-v. Ver apéndice documental.

${ }^{36}$ Ibídem, vol. 145, f. 417r.
} 
Por lo tanto, estos oficiales de la pluma malagueños estaban muy poco valorados por la sociedad de su momento, y ello quedaba reflejado en el salario que percibían por su quehacer, tal y como podemos comprobar por lo ya dicho y por la tabla de salarios que se inserta a continuación. Esta última está extraída de la información que nos ofrecen las Respuestas Generales del Catastro de Ensenada para la provincia malagueña; en ella se ha incluido a un oficial de libros, por ser el único que aparece para toda la provincia malagueña según las respuestas consultadas:

\begin{tabular}{|l|l|l|}
\hline \multicolumn{1}{|c|}{ PUEBLO } & OFICIAL DE PLUMA & \multicolumn{1}{c|}{ UTILIDAD } \\
\hline ANTEQUERA & 16 oficiales & 11.770 reales \\
\hline CAMPILLOS & & 550 reales \\
\hline CAÑETE LA REAL & & 660 reales \\
\hline CASARES & Dos escribientes & \\
\hline ESTEPONA & A cada uno & 2 reales diarios \\
\hline MOCLINEJO & Un oficial de libros & 9 reales diarios \\
\hline TEBA & & 550 reales \\
\hline
\end{tabular}

Tabla 1. Salarios de los oficiales de pluma para la provincia malagueña según las Respuestas Generales al Catastro de Ensenada (1751-1754).

Como se desprende de la tabla antecedente, es muy escasa la presencia de este grupo socio-profesional en la documentación que conforman las Respuestas Generales del Catastro de Ensenada. Además, los nombres son totalmente obviados, y el salario que perciben muy bajo. El salario más alto era el que percibían los oficiales de la ciudad antequerana. Si el montante total lo dividimos entre los dieciséis oficiales que constan, el salario que percibía cada uno de ellos ascendía a algo más de 735 reales de vellón, casi el doble de lo que percibían sus colegas de oficio en la capital malagueña. De hecho, los cuatrocientos reales anuales que ganaban los oficiales del cabildo malagueño es algo inferior a lo que podemos constatar para las ciudades y villas que sí que quedan reflejadas en la documentación tratada, más de quinientos reales tal y como podemos comprobar en la tabla antecedente. A pesar de ello, el trabajo de estos amanuenses estaba poco valorado y esto se reflejaba en el salario que percibían, fuera de 700 o de 500 reales, muy alejado de lo que solían ganar los escribanos numerarios o de cabildo de esas mismas ciudades o villas. En Málaga eran más de dos mil reales ${ }^{37}$, al igual que en Antequera $^{38}$; los fedatarios de Campillos percibían por su labor cerca de los tres

${ }^{37}$ A. G. S., Dirección General de Rentas, Catastro de Ensenada, Respuestas Generales, libro 595, ff. 451r-453v.

${ }^{38}$ Ibídem, libro 560, f. 246v. 
mil reales ${ }^{39}$; en Cañete la Real más de dos mil ${ }^{40}$, y en Teba el escribano público era uno de los que tenían uno de los salarios más elevados dentro de la provincia malagueña ${ }^{41}$.

\section{PARA FINALIZAR}

Como hemos podido constatar en las páginas precedentes los oficiales de pluma de la provincia malagueña a mediados del Setecientos componen un grupo socio-profesional que precisa de un análisis más profundo, pero a pesar de ello se pueden arrojar algunas ideas generales en cuanto a su estatus social y económico se refiere.

Era un grupo amplio en los núcleos de población más nutridos, donde la presencia de la institución notarial estaba más asentada y lo componían un elevado número de escritorios públicos y de cabildo. Todos estos fedatarios precisaban de la ayuda de unos amanuenses u oficiales, que eran en realidad el brazo ejecutor del grueso de la actuación escrituraria que se desarrollaba en aquellos escritorios. $\mathrm{Y}$ a pesar de ello, de ser el brazo ejecutor, era un grupo poco valorado por sus conciudadanos y ello se percibe en el salario que recibían por su labor. Un salario muy por debajo de sus jefes, los escribanos públicos o de cabildo, y que en no pocas ocasiones no les daba para mantener a su familia, lo que traía consigo que se vieran en la necesidad de compaginar esta labor con otro oficio que cumplimentara el salario que percibían. Pero esto también conllevaba un hándicap, y es que en no pocas ocasiones se percibe una desidia en los quehaceres de estos oficiales, lo que conllevaba que las escrituras no estuvieran protocolizadas o firmadas por el escribano, es decir, que en realidad no tuvieran ninguna validez. Tal y como hemos podido comprobar ejemplarizando todo lo que se apunta en la figura de Antonio Paredes y Aguilar.

${ }^{39}$ A. G. S., Dirección General de Rentas, Catastro de Ensenada, Respuestas Generales, libro 561, f. 416r.

${ }^{40}$ Ibídem, f. 462r.

${ }^{41}$ Ibídem, libro 563, f. 544v. 
LORENA BARCO CEBRIÁN

ANÁLISIS DE UN COLECTIVO SOCIO-PROFESIONAL MINUSVALORADO...

\section{APÉNDICE DOCUMENTAL}

Memorial presentado ante el cabildo malagueño por parte de los oficiales de pluma de la escribanía de Francisco Nieto para que se les pague su trabajo. Archivo Municipal de Málaga, Actas Capitulares, Vol. 144, fs. 172v y 177r-178v, año 1753.

La ciudad de Malaga, justicia y reximiento se junto a cavildo en su sala capitular como lo ha de uso y constumbre, en viente y nuebe de marzo de mil setesientos cinquenta y tres años, que lo presidio el señor don Juan Miguel Diez, alcalde maior de esta ziudad.

En este cavildo se uido (sic) el informe del presete escribano puesto en el memorial de Antonio Joseph de Espejo, Don Julian de Fragua y demas oficiales de pluma de la escribania de Don Francisco Nieto, por donde consta que auiendo reconocido los orixinales antiguos de que sean sacado y sacan las copias que constan de dicho memorial taso este trauajo en docientos reales de vellon cuio memorial acuerdo e ynforme se pone en este cavildo y como se sigue a quien el memorial la ziudad entendida acordo de librar a los referidos, doscientos reales de vellón. Y en virtud de testimonio de este acuerdo se les despache libranza sobre los caudales de sus propios por el trauajo que an tenido tomando razon el contador.

Yllustrisima ciudad, Antonio Joseph Espejo, Don Julian de Fragua y demas oficiales de la pluma que de orden de vuestra señoria estan sacando las copias de los reales privilegios que obtiene vuestra señoria puesto a sus pies con la mayor veneración, dizen que teniendo copiados treze reales despachos muy difusos y los mas de letra antigua y mui dificil y estando siguiendo la saca de los demas en lo que han ocupado muchos dias y con un cresido trabajo y siendo notorio no tener otra cosa con que sustentarse sino es con su trabajo personal, se hallan con muchas estrechezes por lo que recurren a la Eroica piedad de vuestra señoria, a quien suplican se digne a librarles con que puedan subbeuir a el remedio de sus atrazos con aquella cantidad que la elevada comprehencion de vuestra señoria reconosca mereser su trabajo, para que assi puedan acavar de servir a vuestra señoria en la dicha saca de copias. Fabor que esperan merecer de la equitativa clemencia de vuestra señoria cuya grandeza prospere Dios en el mayor auge. 